\title{
M. WALZER AND CONTEMPORARY COMMUNITARIANISM ${ }^{1}$
}

\author{
Jarmila Chovancová \\ Comenius University, Faculty of Law
}

\begin{abstract}
The author in her article focuses on the views of M. Walzer, encompassed specifically in his works „Spheres of Justice“ - „The Defence of Equality and Pluralism“, and „The Just and Unjust Wars". The focus is given to equality, pluralism, and justice which represent the main issues considered by the contemporary communitarianism.
\end{abstract}

Key words: equality, complex equality, freedom, justice, society, injustice, democracy

\section{INTRODUCTION OR WHAT IS COMMUNITARIANISM?}

Communitarianism, represented by James M. Buchanan (Theory of the Public Choice) and John Rawls (Theory of Justice), reflects the academic reaction to the academic challenges of the liberal political philosophy in the USA in the seventies of the previous century. Let us compare the bases of liberalism and communitarianism:

Liberal Idea: Individual freedom is the ultimate moral challenge. For a member of an individual society the law with its purpose to organize the strengthened individual freedom enjoys only secondary importance. The state represents an abstract, contract-based system of general and sensitive cooperation between the individuals in their pursuit for profit or justice. Buchanan: the economic dimensions of the private interest represent the main source of reasonable political decisions. ("Theory of Public Choice“; Locke) Rawls: the generalization of the personal interests to abstract levels creates reasonable political decisions.

Communitarian Idea: Not necessarily must the individuals be understood in their whole complexity without their social dimension, the state represents a substantial legal order for the individuals, guaranteed by the society: justice/law represent a true relationship (Plato describes it as „harmony") between an individual and society, between the social responsibility and personal choice; family tradition, belief, education create substantial criteria for decision-making in the meaning of the relevant „Sittlichkeit“ (Rousseau, Hegel).

Who are the Communitarians? This movement consists of variety of distinct and special scientists and activists, e.g. Benjamin Barber (Strong Democracy, 1984), Robert N. Bellah (The Good Society, 1991), Amitai Etzioni (The Spirit of Community, 1994), Hans Jonas (The Genesis of Values, 1997), Alasdair MacIntyre (After Virtue, 1984), Martha Nussbaum (Cultivating Humanity, 1998), Robert Putnam (Bowling Alone,1995), Michael Sandel (Liberalism and Its Critics, 1984), Charles Taylor (The Ethics of Authenticity, 1992), Michael Walzer (The Spheres of Justice,1984). What puts them together is their critical attitude towards the contemporary academic and social developments.

The paper is a partial outcome of the project VEGA 1/0138/18 Marxizmus stále živý? K prehodnoteniu učenia K. Marxa v súčasnom právnom a ekonomickom myslení. 
Critics of Liberalism. Sandel, Taylor, and Walzer represent the main critics of liberalism. It is not their main goal to extinguish the American liberalism as the main representative of the political theory of the contemporary American society, much more they are the followers of both the American civil law and anti-Vietnam war movements, etc. The descendants of the extreme hyper-idealistic views of the initial liberal thinkers, libertarians or utilitarians, who systematically and improperly construed Aristotle in his political engagement and individual position for the benefit of a society formed by the so called "elbow" ethics, belong to this group. Thus, the main argument was to ignite the social dimensions of both the political establishment and life. This is the area of New Hegelianism within the communitarianism movement. Relying on Aristotle, Rousseau and Hegel and their attitudes to the concepts of politics, state and society, this first generation of communitarians tried to object the linear and abstract arguments of the representatives of the one-sided liberalistic conceptions of society and state as not matching the complex political reality of the modern life. So they tried to "add" the dialectically necessary second, or modified argument with the purpose to get closer to the complicated truth of the human existence in a society.

Political activism is represented by the global campaign of Amitaio Etzioni, the establisher of Social Network, having Al Gore, Tony Blair, Gerhard Schroder, Kurt Biedenkopf as its members. This was the attitude of the 90-ties, successful, however, lacking the real academic theoretical grounding, especially in the context where there existed a threat of transforming the communitarian thought into cultural relativism - each culture on the Earth creates (not only by being "culture") more or less similar normative consequences (e.g. against the universal concept of human rights). Such ideas were not the communitarian stratagems, as these understood their commitment towards the community as a dialectic supplement of the classical (not neo-libertarian) liberalism. However, the communitarians needed the new academic research to develop proper argumentation against the neo-liberal, economic "glob-ideology" which was spreading around the world continually.

Thus, the last stage of communitarianism is represented by the intention to bring the systematic development of the general conception within the technically and economically globalized world back to the academic ground. Today, the re-establishment of the communitarian conception of political thought on the academic basis brings about the idea of re-consideration of the sources and the discourse of the political philosophy of the $20^{\text {th }}$ century.

\section{POSITION OF M. WALZER IN COMMUNITARIANISM}

M. Walzer is a cultivated political philosopher and the author of very well-known works, e.g. "Spheres of Justice"; or "Just and Unjust Wars", where he analyses the social distribution of wealth and power, as well as the other social values, e.g. education, work, free time, etc.

M. Walzer and J. Rawls view these issues from different perspectives. J. Rawls, in his analysis of justice, gives precedence to economy and psychology, while Walzer gives more attention to history and anthropology. This defence of history against its deprecation is typical for Walzer - a historian. On the basis of historical analysis, Walzer fosters his key position concerning the development of civil society and democracy. These issues have already been analysed in several fields (philosophy,

2 WALZER, M. Spheres of Justice. Oxford : Basil Blackwell, 1983, p. 34. 
ethics, history, law, etc.), however, we cannot but state that the satisfactory level of theoretical analysis has not yet been reached.

It is obvious, that the concept of democracy has always been connected with the desire to put all its predominant values into practice. However, in reality, it seems rather difficult and problematic. And it is namely the issue of equality and other democratic values in a civil society that Walzer focuses on. We can say that it represents his main goal, while the plurality of thought and real complexity of distribution systems play also a very important role in his work.

In his considerations concerning equality, Walzer highlights the notions of simple and complex equality. ${ }^{3}$ For the purpose of illustration, he presents a society where everything is for sale and all citizens have an equal amount of money. Such a situation is described by Walzer as the "regime of simple equality". Equality as a multiple variable process spreads through a number of chains of further social values.

The "regime of simple equality", however, cannot last for long as the free market exchange definitely brings about inequality. If somebody seeks to preserve the simple equality, he can do it only via a centralized state, alternatively via an active state power (which is also rather difficult and dubious in its result). Many problems, e.g. unwillingness and lack of capacity of the bureaucracy to participate in the aforementioned activity may arise. In practice, breaking the monopoly of money neutralizes its importance.

Also other values step in, whereby the inequality achieves new forms. These forms operate in different ways. For example, in the regime of simple equality, it has been provided that everything is for sale and each person has an equal amount of money. At the same time, everybody enjoys an equal opportunity of investment. Some invest in education, some, on their own discretion, meet a different choice. Purchase, however, is made universal through the system of taxation.

In case of investment into education, as illustrated, the educational institution (the school) becomes a competitive ground.

M. Walzer believes that also in this world of education, the educational success and certificates can become a subject of monopolization by a new group of people, he denotes as the "talented group". The members of this group control the dominant features of the school to the outside. They will take hold of different office posts (grant the academic degrees, etc.) M. Walzer poses a question: What response to choose under such circumstances? He asks whether it is possible to set limits to the new recognized models or whether to force the monopoly of power of the "talented" to observe the stipulated rules.

Here Walzer responds to a different principle presented by Rawls, under which the inequalities are justified only if they bring the greatest benefit to the most disadvantaged social groups.

According to Walzer, simple equality requires a continual state intervention to make the monopolies to observe stipulated rules and supress new forms of dominance. However, there exists a danger, that the state power itself would become a central object of competitive fight. The political power, or politics are always directed towards dominance; this is the most important and dangerous value in the human history.

M. Walzer explains what he understands under the notion of political power. He perceives it as a special kind of value and believes it enjoys a dual character. Firstly, political power belongs to a category of issues freely used by the people due to their momentary importance. Sometimes it is

3 Ibidem, p. 56. 
important and dominant, sometimes it is not. Secondly, the political power as a regulatory phenomenon influences the social values in general.

Political power is used for the protection of borders of all the distributive spheres, including its own, as well as, for the enforcement of the common understanding of what is right or wrong. It is this latter meaning we can be made use of. We can conclude that the political power is always dominant within certain borders, and not without them.

The central problem of the political life is represented by the necessity to preserve the decisive distinctions, as the American put it, between "at" and "in". However, this is a problem which cannot be solved by the given imperatives of simple equality.

Therefrom arises also the need for the agents of pressure creating the constitutional governance and different balances. These borders are very important for a variety of different social and economic monopolies, as well as for their abolishment. M. Walzer believes that the main danger for a democratic government is represented by the new born monopolies with a social power of plutocracy, bureaucracy and technocracy, etc.

In theory, the good dominates the political power, however, in practice, at the breach of power of the monopolies, the dominance of the good is neutralized.

To support his argument, Walzer cites Marx ${ }^{4}$ that democracy is an essential and reflective system, reflecting the predominance of the distribution of the social good.

If the power over monopolies should be preserved, then this power would be centralized or monopolized. Thus, the state must be very strong if it wants to meet the stipulated intentions through the distinctive or differentiated principles. In this context, there can appear certain tension between the new-born monopolies and the political pressure, between the goal to give precedence to the talented, and the pressure of the distinctive, differentiated principle, as well as between the agents of pressure and democratic constitution.

Such problems arise from the negotiating monopoly and not dominance being the main result within the distributive justice. However, this is a different kind of equality. Here we approach the issue of the complex equality.

The arguments for the complex equality, in Walzer's view, find their roots in our understanding of the current, concrete, positive, as well as special character of the social values.

As mentioned above, the simple equality represents a simple distributive condition.

Equality is a complex human relationship, communicating the values we create, we share and divide among ourselves. Thus, it is necessary to distinguish the distributive criterion from the social values.

M. Walzer, for the purpose of illustration, mentions the views of B. Pascal and K. Marx. He takes the argument from Pascal's work The Persées (England, 1961, p. 244) and Marx's Economic and Philosophic Manuscripts (London, 1963, p. 193 - 94).

Pascal expressed his understanding of complex equality in his characteristics of tyranny. "Tyranny stems in the wish to rule the world, even outside its own sphere. Tyranny equals the endeavour to obtain what another could only have. We own different duties, qualities: love is the true answer, reflection of magic, fear of power, belief in wisdom" - these could make tyranny weaker.

$4 \quad$ Ibidem, p. 61. 
Marx in his early work shares this view. ${ }^{5}$ The relation of a human to a human and to the world is humane. Love can be exchanged only for love, etc. These are the borders and possible limits to tyranny.

If you wish to enrich and move arts further, you must be an artistically cultivated person, if you wish to influence other people you must enjoy the capacity to exert impact on others.

I believe that the example related to the complex equality was chosen by Walzer deliberately in order to highlight its foremost goal, i.e. the focus on the personal qualities and social values having their own spheres of operation. The social opinion represents a special value, which is well observable in the political sphere. According to Pascal, in the political terminology, it is not the ruler who orders what is right or wrong with the thoughts, even though he may think so due to the fact that he is in power.

In Marx's opinion, it is the right goal that gives direction to my conduct, to my deeds. If the ruler wants to put something into practice, he must be convincing, practical, initiative, etc. These arguments depend on the power - its share of influence, its understanding and comprehension. The social values have a social grounding, the way to the distributive justice can be found through their interpretation.

The first goal is to look for the internal principles of every distributive sphere.

The second one is contained in the warning that not enough attention is paid to the principles leading to tyranny, which is shown in the abuse of political power.

The regime of the complex equality represents a counterpart to tyranny.

The complex equality creates a structure of relationships where the dominance becomes impossible. M. Walzer believes that the distributive principle seeks to investigate the perception of the social values, as well as to research the internality of the distributive spheres.

He highlights the fact that the modern democracy is based on two requirements: the first one is the universal wish of the people to decide on their own issues, or, at least, to co-decide on who would decide on them. Liberalism represents the second requirement; it is understood as a set of social and political beliefs, positions and values presuming the universal, i.e. equal, application of law.

The structural and functional relations and processes suffer due to the existence of pluralism in definition of the contents of democracy.

Walzer believes that it is necessary to pursue pluralism while, at the same time, to require a coherent protection of the pluralistic views.

To put it simply, there must be principles, which are fair in view of the selection and arrangement of their limits.

In connection to pluralism, we are not required to approve all the distributive criteria or to accept every possible agent.

M. Walzer expresses critical views to majority of philosophers who elaborated on the problem of justice, Plato being the first of them, in connection with the existence of the sole and only distributive system according to which philosophy can correctly operate.

Currently, this system is mostly described as one of the ideally rational systems where the people, in their quest to find impartiality, are totally unaware of their own situation, of particular goals confronted with the abstract structure of values.

5 MARX, K. Economic and Philosophic Manuscripts. In Karl Marx : Early Writings. London : Watts, 1963 , p. 193. 
Particularism of history, culture and other relations represents, however, a more critical issue. The problem what a reasonable person understands under the concept of universal conditions gains more and more importance. What do individuals from our own strata seek in their participation in culture while being determined by this participation? Do these questions transform into the choices we make during our common life?

Another problem arises in this context. Justice represents a human characteristic, thus, as we are very different, it is highly disputable whether it can be established only in one way. This is the moment of philosophical approach, Walzer focuses on. The questions stemming in the theory of distributive justice allow for many answers, and also provide for a possibility of cultural diversity and political choice. Not only the simple principle or principles of various historical approaches can be implemented in this way. There is no doubt that there exist a lot of morally admissible implementations.

M. Walzer, first of all, stresses the fact that the principles of justice themselves are of pluralistic character, more precisely, they enjoy the pluralistic form. The different social values resulted from different procedures, different agents and all these differences are derived from the different understanding of the social good as such, which represents an unavoidable product of both the historical and cultural particularism.

According to Walzer, the theories of distributive justice focus mainly on the social processes. The distributive notion is understood as a concept to give, allocate, exchange. The main focus is not given to the producers and consumers, but to the distributive agents, as well as to the recipients of values. People are always interested in themselves, especially in situations when they are in positions of persons giving and persons taking. Inevitably, they face the following questions: What represents our substance? What are our rights? What do we need? All these questions are related to the distributive principles presuming the control of the movement of values.

M. Walzer describes the process, which he considers dominant, precisely and in its complexity. It is a process where the people think and create values which they later distribute among themselves. The values and the concept of the Good do not appear unexpectedly and without any control. The human comprehension is a critical and decisive medium of the social relations entering the human mind earlier than human hands.

By focusing his attention on the concept of distributive justice itself, M. Walzer does not underestimate the role of a human agent. He tries to explain and specify the distributive principles into 6 presumptions:

1. All the Good that is concentrated in the distributive justice represents social values. The concept of the Good is conditioned by the social opinion. The same rational perception of the Good enjoys different perceptions in different societies. The same "thing" is evaluated by different reasoning, it can be considered priceless here and worthless there.

2. "The state of - this is me and this is mine" is very difficult to describe. History plays very important role in this context. In reality, there exists a certain history of transactions not only among people, but also in the perspective of their interaction with the moral and material world they live in. Without history, there would be no sensible recognition of the existence and reasonableness of distribution.

3. This is not a simple structure of primary values or perception of the Good we acquire via the moral and material world. It is a well-known truth that the question is much more difficult than the answer. The answer can be incorporated only if we abstract from different views. 
4. Distribution can be just or unjust. It represents a relative relation to the social perception of the Good the distribution is connected to. These encompass the ways and principles of legitimacy, as well as the critical principle.

5. The social opinion has its own historical perspective, so the distributions, weather just or not, change from time to time. A certain clue to understanding the Good can be found in the normative structures, in the concrete time and space lines.

6. If the opinions vary, the distribution must be autonomous. Each social Good is constituted by the distributive sphere with a certain number of organized criteria.

In connection with the issue of pluralism, Rawls' theory of justice equalling to decency and a form of political liberalism, is considered by many as defining the political institutions as instrumental and serving the purposes of individuals and associations.

J. Rawls denounces this objection stating that the conception of justice as decency resigns to the ideal of political sociability if, this ideal, is only coupled with the religious, moral and philosophical doctrine. Pluralism, per se, excludes such a conception. In Rawls's extended consensus, a political conception is confirmed by citizens recognizing different doctrines.

Rawls $^{6}$ believes that if we allege that some society is well governed by a certain conception of justice, the main presumption is that it is a society where all the citizens accept and mutually recognize the same principles of justice.

Further, he anticipates that its main structure, the main political and social institutions are accountable to the stipulated principles, and that the citizens enjoy the awareness of justice, apply these principles, and act accordingly. Such a social unity represents the most effective and, in practice, optimal concept of unity.

However, according to Walzer, the plurality of theoretical thought, as well as the usage of terminology by which the structures, relations and operation of the society are expressed and evaluated, do not define their weakness or strength.

Along with the issue of simple equality, $\mathrm{M}$. Walzer, on the comparative level, considers also the issue of complex equality. The arguments related to complex equality root in the position of our understanding, the current, positive perception of various social values, including the aspects of concreteness and particularity.

As already mentioned, simple equality represents a simple distributive condition. Equality itself is a complex relationship among people through which the values are communicated and created. However, it does not represent the identity of property. The distributive criterion, reflecting the distinction of the social values, plays an important role here.

M. Walzer puts the main stress on the three distributive principles, i.e.: free exchange, credits and needs. These principles enjoy the real power and are the substantial pillars of distribution.

Firstly, we would like to elaborate on the issue of the three aforementioned distributive principles, then, we will express our view to complex equality.

Walzer understands the free exchange as an open and, at the same time, a closed structure. He believes, that in the free process of exchange it will be possible to anticipate the specific division of the social values and, at the same time, it will be possible also to predict the general structure of division. On the theoretical level, the free exchange creates a market where all the values can be ex-

6 RAWLS, J. A Theory of Justice. Cambridge Mass : Harvard University Press, 1971, p. 77. 
changed for all the other values through a neutral medium - money. No values or monopolies are dominant in this context. Every exchange represents an expression of social opinion. The market, in its very basis, is radically pluralistic and in its operations and inputs very sensitive, especially in connection to the individual values.

M. Walzer imposes a question: What can interfere with the free exchange in the name of pluralism?

It is necessary to keep in mind that the everyday operation on the market, the real and current experience of the free exchange very much differs from the presumed theory.

Money is considered a neutral medium which represents a dominant value in the real life and is monopolized by those enjoying a special talent in the business sphere. There arises a situation where other people, not enjoying this talent, require a re-distribution of money to establish the system of simple equality. However, when we focus on the first and non-problematic moment of simple equality - the free exchange on the basis of equal shares - we will always need certain limits setting the possibilities of exchange, i.e. what can be exchanged for what.

\section{$3 \quad$ POLITICAL POWER ACCORDING M. WALZER}

Political power is used by Walzer for the purpose of illustration. He defines the political power as a system of values having a volatile price, votes, influence, offices, etc. Some of these values can become a subject of trade on the market and accumulated by the willing persons to sacrifice them in favour of other values. Always, when the sacrifice becomes real, it results in a certain form of tyranny - more precisely, the minute tyranny establishing the conditions of simple equality.

There can be doubts, and in reality they really do exist, whether the result is tyrannical from the standpoint of two or more persons who should reach the voluntary agreement.

It is definitely tyrannical from the standpoint of other citizens who are subjected to my disproportionate power. Walzer further believes that in a democratic society the democratic politicians sometimes buy the votes or, at least, try to win over the voters by giving promises, or by directing the public expenditures to specific voluntary groups of voters.

Free exchange is not a general criterion. Only extensive analysis, preferably based on the philosophical and not the authoritative system, make it possible to specify its limits. It is known that money have no limits - this is the primary form of the monetary cycle. The attempt to prevent their uncontrolled operation is the matter of convenience, as well as principle. Omission of this rational standpoint has its consequences through the chain of distributions.

Similar to the free exchange, also the credits enjoy the open-closed and pluralistic character.

M. Walzer asserts that it is always the ruling group that sets the criterion of credit.

Credit is the dominant goal, however, it also presumes and seeks objective judgment. Who is in the society authorized to regulate the distribution of influence within the bureaucracy, in the artistic sphere, and in politics? What should the criteria be? How can a person deserve to be instated in certain position? How can his objectivity be guaranteed?

According to Walzer, God is the only one who can read the secrets of human hearts. He is the only one capable of making important distributions. 
If this task is done by people, the distributive mechanism is seized mainly by the aristocratic group. Afterwards, the credits cease to be a pluralistic criterion. M. Walter states that: "we will find our own face in the face of a new order (the old type) of tyrants."

And eventually, the criterion of needs: "To each according to his needs" is generally understood as the distributive half of Marx's maxim: Let's distribute the social wealth so that the needs of its members are fulfilled.

In reality, the first half of the maxim represents a distributive offer and does not provide for order within the second half of the maxim.

"To each according to his needs" presumes the work to be distributed on the basis of individual qualifications. However, the individuals usually do not experience the need to perform work for which they are qualified. Such type of work is very rare and there are a lot of qualified candidates to perform it. Who are the candidates who need it most?

What about the commission? What are the criteria of its decision-making? Walzer finds one question very interesting, i.e. what does the commission for selection of a director of a hospital in its decision-making prefer? Is it the qualification of candidates or the needs of patients? He concludes that a set of needs, if not based on the political controversy, will always lack simple distributive decision. He alleges that, after all, the Marx's maxim does not, in reality, facilitate the real distribution of political power.

Using the children's terminology, expressed in the concept of "I want", we need to recognize that we still would not acquire an adequate distributive criterion. Not everybody considers the honours, fame, valuable books as needs.

The examples enumerated by Walzer cannot be distributed equally among people having the same desires, as some of them are of general character while others are more or less important in view of the rational ownership.

The needs generate a specific distributive sphere with its own reasonable distributive principle.

Every founded criterion encounters a general rule in its own sphere. Basically, it is an effective rule distinguishing the values of distinctive groups of people based on different rational explanations and different procedures. This situation, eventually, represents the mapping of the entrance to the social world.

Walzer gives special attention to the social world. The analysis he provides enjoys the phenomenological character. It is not the ideal mapping that he pursues, his goal is much more to provide an analysis adequate to people and their reflection of life. Reflexion is the goal, of course, a special reflection stressing the understanding of the social values which are not predominantly reflected in the everyday practice. However, absence of the effort to attain such an understanding and comprehension would also represent a problem.

M. Walzer believes, that, for a very long time, the social understanding has been seeking the autonomy or the relative autonomy of the distributive spheres. It is not impossible to imagine a society where the dominance, as well as the role of the monopolies, is not breached. In this context, Walzer pays attention to the social castes (India). He understands them as strictly divided groups in a pluralistic society. The system of castes is constituted on an exceptional integration of the social opinion. Prestige, wealth, knowledge, bureaucracy, occupation, etc. - they all represent social values which are integrated in both the intellectual, as well as, natural hierarchies. The hierarchy itself determines the simple values of ritual purity. 
Some kind of collective mobility, which can cultivate the outside markets highlighting the strict limits and presuming the rise of their position on the social scale, is possible for castes and subcastes.

The system as a whole rests on the religious doctrine promising the equality of chances not in this life, but through the lives of the soul. The individual status "here and now" represents the consequence of its conduct in the last incarnation. If the status is not satisfactory, it can be remedied by achievement of some credits in the current life, thus increasing its potential for the future. The distribution "here and now" is a part of a simple system, where the purity represents the predominant value. The birth and blood are dominant in the entire purity. All the values are as laurels in the hereditary monarchies. This is not the forum or criterion of the autonomous distributions.

The social understanding within the dimension of the imperial power encompasses some of the concepts of the God's favour, magic talent or human empathy. These represent the criteria for the ruling bureaucracy, potentially independent from the descent and blood. The social values are not integrated fully into bigger systems which are comprehensive only within their own terminology and mentality of the pertinent nation. The theory of values explicates the understanding of this type of values according to the system of their operation.

Tyranny always has a specific character, specific overstepping of the border, specific desecration of the social opinion.

The complex equality demands the protection of borders, as it works with a different type of values, as well as with different people. According to Walzer, we can speak only about the "regime" of complex equality due to existence of more limits. Simple equality is simpler. One dominant Good is distributed and makes the society egalitarian. Complex equality is, however, more complicated. Within these dimensions and limits of the complex equality, Walzer poses a question: What values must be autonomously formulated to become communicative relations of the equality among people? The answer to this question is not unequivocal and, consequently, there is no possibility to establish an ideal regime.

\section{CONCLUSION}

The social values are distributed and exchanged also through the political diversity. In a concrete society, the monopolies operate along these borders, but also within them. The political community is principally a closed one and can be entered into only through the world of common understanding. The language, history and culture together create the collective awareness. The national character created as a fixed and permanently mental order is predominantly a myth. Usually, it lacks the aspect of sensitivity and intuition within a society which represents the expression of the real life. In the contemporary world, the number of states where there exists no moment of sensitivity or intuition is on the rise. These attributes characterise mostly smaller states. In this situation, if we want our arguments to achieve the moral basis, it is necessary to appeal to the understanding of the cultural diversity and local autonomy. However, this is not just a task for philosophers, but for all of us, including, first of all, the politicians. 


\section{Bibliography:}

MARX, K. Economic and Philosophic Manuscripts. In Karl Marx : Early Writings. London : Watts, London, 1963. RAWLS, J. A Theory of Justice. New YorkCambridge Mass : Harvard University Press, 1971.

WALZER, M. Spheres of Justice. Oxford : Basil Blackwell, 1983.

\section{Contact information:}

prof. PhDr. Jarmila Chovancová, CSc.

jarmila.chovancova@flaw.uniba.sk

Department of Theory of Law and Social Sciences

Faculty of Law, Comenius University in Bratislava

Šafárikovo nám č. 6

81000 Bratislava 1

Slovak Republic 